\title{
Type B Aortic Dissection
}

\section{A Review of Prognostic Factors and Meta-analysis of Treatment Options}

\author{
Thomas Luebke, MD, PhD*, Jan Brunkwall, MD, PhD \\ Department of Vascular and Endovascular Surgery, University Hospital of Cologne, Cologne, Germany
}

Based on a Presentation at the 2013 VEITH Symposium, November 19-23, 2013 (New York, NY, USA)

\begin{abstract}
According to international guidelines, stable patients with uncomplicated Type B aortic dissection (TBAD) should receive optimal medical treatment. Despite adequate antihypertensive therapy, the long-term prognosis of these patients is characterized by a significant aortic aneurysm formation in $\mathbf{2 5 - 3 0 \%}$ within four years, and survival rates from $\mathbf{5 0}$ to $\mathbf{8 0} \%$ at five years and $\mathbf{3 0}$ to $60 \%$ at 10 years. In a prospective randomized trial, preemptive thoracic endovascular aortic repair (TEVAR) in patients with chronic uncomplicated TBAD was associated with an excess early mortality (due to periprocedural hazards), but the procedure showed its benefit in prevention of aortic-specific mortality at five years of follow-up. However, preemptive TEVAR may not be the treatment of choice in all patients with uncomplicated TBAD because of the inherent periprocedural complications like stroke, paraparesis, and death, as well as stent graft-induced complications (i.e., retrograde dissection or endoleaks). Thus, the TEVAR-related deaths and complications (especially paraplegia and stroke) raise concerns that moderate the better survival with TEVAR at five years. By timely identification of those patients prone for developing complications, early intervention, preferably in the subacute or early chronic phase, may improve the overall long-term outcome for these patients. Therefore, early detectable and reliable prognostic factors for adverse events are essential to stratify patients who can be treated medically and those who will benefit from rigorous follow-up
\end{abstract}

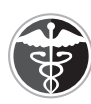

Fax +1 2037853346

E-Mail: aorta@scienceinternational.org

http://aorta.scienceinternational.org (c) 2014 Aorta.

Published by Science International Corp. ISSN 2325-4637

Accessible online at:

http://aorta.scienceinternational.org and, in the long-term, from timely, or even prophylactic, TEVAR. Several studies have identified prognostic factors in TBAD such as aortic diameter, partial false lumen thrombosis, false lumen thickness, and location of the primary entry tear. Combining these clinical and radiological predictors may be essential to implement a patient-specific approach designed to intervene only in those patients who are at high risk of developing complications to improve the longterm outcomes of patients with uncomplicated Type B aortic dissection. Copyright @ 2014 Science International Corp.

\section{Key Words}

Type B aortic dissection - Endovascular • Thoracic aorta

\section{Introduction}

With respect to hospital-based studies performed in western countries, the incidence of acute aortic dissection is suggested to be 3-5 per 100,000 cases per year, with an increasing incidence during the past decades $[1,2]$. According to international guidelines, stable patients with uncomplicated Type B aortic dissection (TBAD) should receive optimal medical treatment $[3,4]$. Patients without medical therapy with acute TBAD are reported to have an early mortality rate of $>50 \%$. Due to severe complications such as rupture or malperfusion, mortality is highest within

*Corresponding author:

Thomas Luebke

Department of Vascular and Endovascular Surgery

University Hospital of Cologne

50937 Cologne, Germany

Tel.: 0049221478 32429, Fax: 0049221478 32499; E-Mail: Thomas.luebke@uk-koeln.de 
the first 7 days after TBAD [5]. The combined neurological complication rate within 30 days of medical management is reported to be approximately $10 \%$ $[6,7]$. In selected patients, effective antihypertensive therapy results in promising in-hospital survival rates of $90 \%$ to $98 \%[2,8,9]$ and early annual survival rates $\geq$ $80 \%[3,10-12]$.

However, despite adequate antihypertensive therapy, the long-term prognosis of these patients is worse compared to the 30-day outcomes with significant aortic aneurysm formation in $25-30 \%$ within four years, an estimated rupture rate of $30 \%$ once aortic expansion reaches $60 \mathrm{~mm}$ [13], and survival rates from 50 to $80 \%$ at five years and 30 to $60 \%$ at 10 years $[14,15]$. Therefore, best medical management may only delay progressive aneurysmal degeneration [1618].

Data from the International Registry of Aortic Dissection (IRAD) indicated high mortality, with $25 \%$ of patients dying within three years after acute Type $B$ dissection. After discharge, an estimated $31-66 \%$ dissection-associated deaths occurred (referring to the overall deaths), caused by rupture or perioperative mortality from aortic repairs [15,19-21].

\section{Complicated TBAD}

In the acute phase rupture, malperfusion, hemorrhagic pleural effusion, periaortic hematoma, refractory pain, and hypertension define complications of TBAD [6]. The results from IRAD demonstrated that in $24 \%$ of patients with Type B dissection, emergent surgical intervention for early complications was necessary within the acute setting of 14 days, and that in-hospital mortality was significantly higher in patients with refractory pain and hypertension compared to patients without these clinical signs $(17.4 \%$ versus $4 \%$ ) [22].

During the chronic course of TBAD, complications are characterized by aneurysmal dilation $>55 \mathrm{~mm}$, an aortic yearly increase of $>4 \mathrm{~mm}$, or a recurrence of symptoms despite best medical therapy [6].

\section{Uncomplicated TBAD}

\section{Chronic Uncomplicated TBAD (INSTEAD)}

The first randomized trial of elective thoracic endovascular aortic repair (TEVAR) in patients with chronic uncomplicated TBAD, the INvestigation of STEnt grafts in patients with type B Aortic Dissections (INSTEAD) trial, did not demonstrate a significant difference in the 2-year cumulative survival data between best medical treatment and endovascular repair [23].

In detail, there was no difference in all-cause deaths, with a 2-year cumulative survival rate of $95.6 \pm$ $2.5 \%$ with optimal medical therapy versus $88.9 \pm 3.7 \%$ with TEVAR $(P=0.15)$; the trial, however, turned out to be underpowered. Moreover, the aorta-related death rate was not different $(P=0.44)$, and the risk for the combined end point of aorta-related death (rupture) and progression (including conversion or additional endovascular or open surgery) was similar ( $P=$ 0.65). Other procedural and periprocedural lethal complications in the patients with chronic uncomplicated TBAD $(n=72)$ included postprocedural rupture of access vessel $(n=1)$, abdominal redissection with intestinal malperfusion $(n=1)$, postprocedural Type $A$ dissection with pericardial tamponade $(n=1)$, fatal hemorrhagic stroke $(n=1)$, sudden cardiac death (ventricular fibrillation) ( $n=1)$, and pulmonary embolism $(n=1)$. Three neurological adverse events occurred in the TEVAR group (1 paraplegia, 1 stroke, and 1 transient paraparesis), versus 1 case of paraparesis with medical treatment. Finally, aortic remodeling (with true-lumen recovery and thoracic false lumen thrombosis) occurred in $91.3 \%$ of patients with TEVAR versus $19.4 \%$ of those who received medical treatment $(P<0.001)$. As a result, at two years, the study concluded that optimal medical therapy for chronic uncomplicated TBAD has very good survival results although close computed tomography surveillance is mandatory [24,25]. In contrast to these 2-year results, the long-term results showed an improved outcome for TEVAR [26]. In detail, the risk of all-cause mortality (11.1\% versus $19.3 \% ; P=0.13)$, aorta-specific mortality (6.9\% versus $19.3 \% ; P=0.04)$, and progression $(27.0 \%$ versus $46.1 \%$; $P=0.04$ ) after five years was lower with TEVAR than with optimal medical treatment alone. Landmark analysis suggested a benefit of TEVAR for all end points between two and five years; for example, for all-cause mortality (0\% versus $16.9 \% ; P=0.0003)$, aorta-specific mortality ( $0 \%$ versus $16.9 \% ; P=0.0005)$, and progression ( $4.1 \%$ versus $28.1 \% ; P=0.004)$. Landmarking at 1 year and 1 month revealed consistent findings. Both improved survival and less progression of disease at five years after elective TEVAR were associated with stent graft-induced false lumen 
thrombosis in $90.6 \%$ of cases $(P<0.0001)$. Additionally, during the follow-up period there was a crossover from the medical to the endovascular treatment group in $21.2 \%$ of cases [25].

In summary, in this study setting, preemptive TEVAR was associated with an excess early mortality (due to periprocedural hazards), but the procedure showed its benefit in prevention of aortic-specific mortality at five years of follow-up, with a number needed to treat of 13; that means 13 patients with chronic uncomplicated TBAD have to be treated by TEVAR to prevent one additional aortic-specific mortality during follow-up [27].

\section{Acute Uncomplicated TBAD (ADSORB)}

The Acute Dissection: Stent-graft OR Best medical therapy (ADSORB) European randomized, controlled trial included patients with an acute uncomplicated TBAD (symptoms $<14$ days). The primary composite end point was incomplete or no false lumen thrombosis at one year; aortic dilatation of $\geq 5 \mathrm{~mm}$, or a maximum diameter of the descending aorta of $\geq 55$ $\mathrm{mm}$ at one year; aortic rupture (thoracic or abdominal aorta) at one year; disruption of the thoracic or abdominal aorta with fresh blood outside the adventitia observed on computed tomography (CT) scan or other radiological modality at any time up to one year. Each of the conditions listed above could on its own result in fulfillment of the primary end point. By choosing this composite end point, sample size calculation showed that a sample size of 60 patients (30 per group) would be sufficient to provide $86 \%$ power to test the primary hypothesis under the intention-totreat analysis. This sample size also provided $>90 \%$ power for the evaluation of the test using the per protocol analysis, assuming a 10\% rate of protocol violations. The analysis of the primary end point was based on the intention-to-treat principle.

At 1 year, 15 (50.0\%) of the 30 TEVAR + BMT (best medical therapy) patients and all 31 BMT patients $(P<$ 0.001 ) had at least one end point event (Table 1 and Table 2).

During the first 30 postoperative days, there were no deaths, strokes, or cases of paraplegia in either group and, during follow-up, there was only one death in the endovascular group, caused by cardiac arrest which was not reported as dissection related; however, no autopsy was performed. One patient in the medically treated group developed a retrograde
Table 1. Percentage of False Lumen Thrombosis by Treatment Group and On Intention-to-Treat Basis

\begin{tabular}{lclr}
\hline & TEVAR + BMT & BMT & $p$ \\
\hline $\begin{array}{l}\text { Composite End } \\
\text { Point }\end{array}$ & $15 / 30(50.0 \%)$ & $31 / 31(100.0 \%)$ & $<0.001$ \\
No False Lumen & & & \\
$\quad$ Thrombosis & $13 / 30(43 \%)$ & $30 / 31(97 \%)$ & $<0.001$ \\
Aortic Dilatation & $11 / 30(37 \%)$ & $14 / 31(45 \%)$ & 0.500 \\
Aortic Rupture & $0 / 30(0 \%)$ & $0 / 31(0 \%)$ & \\
\hline
\end{tabular}

All $p$-values are derived from a two-sample chi-square test.

Table 2. Per Protocol Analysis at 1 Year

\begin{tabular}{lccc}
\hline & TEVAR + BMT & BMT & $p$ \\
\hline & $16 / 31$ & $30 / 30$ & $<0.001$ \\
Due to Event & 5 & 22 & \\
Incomplete & 11 & 8 & \\
No False Lumen Thrombosis & $14 / 31$ & $29 / 30$ & $<0.001$ \\
Due to Event & 4 & 21 & \\
Incomplete & 7 & 8 & \\
Aortic Dilatation & $11 / 31$ & $14 / 30$ & 0.1 \\
Due to Event & 2 & 7 & \\
Incomplete & 8 & 5 &
\end{tabular}

Only patients eligible for evaluation are reported. The $p$-values were calculated by two-sample chi-square test.

Type A dissection. A total of $16.1 \%$ of patients crossed from the medical treatment to the endovascular treatment group.

Incomplete false lumen thrombosis was found in $13(43 \%)$ of the TEVAR + BMT group and $30(97 \%)$ of the BMT group $(P<0.001)$. Aortic dilatation was found in $11(37 \%)$ of the TEVAR + BMT patients and $14(45 \%)$ of the BMT patients. No aortic ruptures were reported within 365 days of randomization in either treatment group $[25,28]$.

There was no baseline difference between the two groups in average maximum false lumen diameter (TEVAR + BMT $23.9 \mathrm{~mm}$ versus BMT $22.1 \mathrm{~mm}, P=$ $0.791)$ or in maximum true lumen diameter (TEVAR + BMT $22.5 \mathrm{~mm}$ versus BMT $23.6 \mathrm{~mm}, P=$ 0.83). However, at the 1-year follow-up, the average maximum false lumen diameter was $18.5 \mathrm{~mm}$ for TEVAR + BMT versus $25.1 \mathrm{~mm}$ for BMT, $P<0.001$; the maximum true lumen diameter was $32.2 \mathrm{~mm}$ for TEVAR + BMT versus $25.5 \mathrm{~mm}$ for BMT, $P<0.001$.

The maximum false lumen diameter decreased in the BMT + TEVAR group by $-7.0 \mathrm{~mm}$ compared to an 
increase of $4.3 \mathrm{~mm}$ in the BMT group $(P<0.001)$. The maximum true lumen diameter increased in the BMT + TEVAR group by $8.4 \mathrm{~mm}$ compared to $1.9 \mathrm{~mm}$ for BMT $(P=0.022)$.

The overall transverse diameter was the same at the beginning; however, after 1 year the transverse diameter in the BMT group remained the same, but that of the BMT + TEVAR group decreased in size (TEVAR + BMT $38.8 \mathrm{~mm}$ versus BMT $42.1 \mathrm{~mm}, P=$ $0.062)$.

\section{Preemptive Surgery and Risk Stratification}

Most patients with acute uncomplicated TBAD will survive by best medical treatment alone. The favorable results associated with TEVAR for complicated TBAD has generated interest in its prophylactic application to treat uncomplicated dissections before the aorta becomes dilated and increases the risk of rupture.

However, the role of prophylactic TEVAR in improving outcomes of uncomplicated TBAD remains controversial.

Prophylactic TEVAR in uncomplicated Type B dissections should prevent future complications, especially late aortic aneurysmal degeneration. To the contrary, TEVAR in uncomplicated patients with Type B dissection may not be beneficial for all patients because of the associated periprocedural and late risks. These include death, aortic rupture, stroke, paraplegia, device collapse, conversion to retrograde Type A dissection, new entry tears related to the device, endoleaks, and a high reintervention rate. Additionally, the long-term benefits of TEVAR may not be achievable in older patients [25].

By timely identification of those patients prone for developing complications, early intervention, preferably in the subacute or early chronic phase, may improve the overall long-term outcome for these patients [25]. Therefore, early detectable and reliable prognostic factors for adverse events are essential to stratify patients who can be treated medically and those who will benefit from rigorous follow-up and, in the long-term, from timely and even prophylactic TEVAR.

The current therapeutic strategy of waiting until the criteria for surgical or endovascular repair are met seems to jeopardize some patients $[15,21,29]$, and

Luebke, T. et al. some patients may risk the possibility of endovascular repair if not identified at an early stage.

Some studies have identified prognostic factors in TBAD such as aortic diameter, partial false lumen thrombosis, false lumen thickness, and location of the primary entry tear [30-33]. However, most of the outcomes of TEVAR have been reported in mixed pathology, including both acute and chronic dissections $[34,35]$, as well as exclusively for acute Type B dissection [36]; but few separate data exist to characterize the outcome of TEVAR exclusively in the setting of uncomplicated Type B dissection. In light of these shortcomings, INSTEAD-XL endorses recent observational evidence [27,37], suggesting long-term benefit for TEVAR in subacute and chronic dissections $[27,38-$ 40].

Patient characteristics, biomarkers, radiological signs, and clinical symptoms have been investigated to distinguish these different subsets of patients, and a review of the recent literature is presented below $[32,41,42]$.

\section{Clinical Predictors}

Recurrent and refractory pain or refractory hypertension may be signs of extending dissection or impending rupture. Multiple logistic regression analysis of the IRAD data showed that refractory pain or hypertension was an independent predictor of inhospital mortality (odds ratio [OR] 3.3). In this cohort, age $\geq 70$ years (OR 5.1) and absence of chest pain on admission (OR 3.5) were also predictors of death [25].

Further clinical variables found to be predictive for aortic growth were age $<60$ years, white race, Marfan syndrome, and a fibrinogen-fibrin degradation product level of $>20 \mathrm{mg} / \mathrm{mL}$ at admission [32,43-46].

Increasing age ( $>60$ years), appropriate blood pressure control (systolic blood pressure $<120 \mathrm{~mm} \mathrm{Hg}$ ), tight heart rate control ( $<60$ beats $/ \mathrm{min})$, and the use of calcium-channel blockers were associated with less aortic growth and rupture [44,46-48]. Across the studies, the influence of age seems to be contradictory. A possible explanation for this observation may be the structure and nature of the aortic wall degeneration with the aortic wall becoming less elastic due to the increased occurrence of atherosclerosis over time. On the other hand, aortic dissection in younger patients may identify a patient subgroup with a higher chance 
of genetic abnormalities that contribute to degeneration of aortic elastic elements over time.

Other laboratory factors, such as thrombinantithrombin III complex, D-dimer, platelet count, and coreactive protein were not associated with aortic enlargement [45].

\section{Radiological and Morphological Predictors}

Morphological characteristics seem to predict aortic dilatation in TBAD treated medically [25].

\section{Aortic Diameter}

In many cases, complications are connected with aortic enlargement, and maximal aortic diameter may suggest abnormal aortic extensibility, blood flow turbulence, or wall shear stress. In several reports, a maximum aortic diameter of $>40 \mathrm{~mm}$ in the acute phase was identified as a predictor of aortic growth, whereas a diameter of $<40 \mathrm{~mm}$ was a negative predictor [3,30,49-51]. Analysis of patients in the IRAD registry demonstrated that complications of dissection were more common in patients with an aortic diameter of $5.5 \mathrm{~cm}$ or greater, and that the in-hospital mortality for patients with an aortic diameter $\geq 5.5 \mathrm{~cm}$ was approximately 4 times greater than those with a diameter $<5.5 \mathrm{~cm}$ [52].

In contrast to these findings, the IRAD data showed that an initial diameter of $<40 \mathrm{~mm}$ was predictive for aortic expansion during follow-up, as well [44]. These findings suggest that, besides patients with a high initial aortic diameter, patients with a lower initial aortic diameter may also present with an important aortic growth and therefore should be monitored more closely than previously assumed.

Most studies define aortic enlargement as a maximum diameter of the dissected aorta of $>60 \mathrm{~mm}$ or rapid enlargement of $>10 \mathrm{~mm} / \mathrm{yr}$, or both, because this rules surgical repair $[25,53]$.

The multivariate analysis of the data by Grommes et al. [54] identified aortic diameter $(P=0.004$; hazard ratio $[H R], 1.07)$ and age $(P=0.038 ; H R, 1.05)$ as independent risk factors that significantly reduced survival. Patients aged more than 66 years with a maximum aortic diameter $>40 \mathrm{~mm}$ at admission had a 6.87-fold higher mortality risk than younger patients and patients with smaller aortic diameters. These findings are in agreement with those of Onitsuka et al.
[55], whose data suggested that older patients take advantage of more aggressive therapy in the initial treatment of uncomplicated dissections to prevent conditions that necessitate later chronic phase surgery.

\section{False Lumen Diameter and Configuration}

Song et al. [32] demonstrated that an initial false lumen (FL) diameter of $>22 \mathrm{~mm}$ in the upper thoracic descending aorta on the initial computed tomography scan was an independent predictor for late aortic enlargement during follow-up with $100 \%$ sensitivity and $76 \%$ specificity. Once the aortic diameter exceeds $60 \mathrm{~mm}$, the risk of false lumen rupture is estimated at $30 \%$ per year $[13,56]$. In addition, the configuration of the false lumen is believed to reflect the pressure inside it. An elliptical configuration of the true lumen in combination with a circular formation of the false lumen was reported to be associated with increased aortic growth [46].

\section{False Lumen Thrombosis}

Several studies have described the presence of blood flow in the FL as a predictor of aortic growth $[48-51,55,57]$ and it was reported to be an independent predictor of postdischarge mortality [31]. A patent FL causes direct hemodynamic stress and structural weakening of the aortic wall, which might induce progressive growth of the affected aortic segment, whereas a completely thrombosed FL has been associated with less aortic enlargement and even aortic wall remodeling $[49,50,58]$.

However, the FL status is a controversially debated predictor for aortic growth and aortic-related death $[15,31,59,60]$. An IRAD report documented the association between partial FL lumen thrombosis and lower survival at three years during follow-up in TBAD patients [31]. In concordance with the IRAD findings, Tsai et al. [31] reported an increased mortality during follow-up among patients with partial FL thrombosis, as did more recent studies [58]. Other groups [58] did not find a relation between partially thrombosed $\mathrm{FL}$ and aortic enlargement and they showed that growth rate was not increased for patients with partial FL thrombosis. In contrast to these studies, more recent studies did show partial lumen thrombosis was predictive for aortic growth [46,61].

Independent risk factors for incomplete thrombosis in the false lumen include visceral branches that 
arise partially or totally from the false lumen (OR 10.1), reentry tears (OR 30.7), and the maximum diameter of the false lumen of the abdominal aorta (OR 1.3) $[25,62]$. Sueyoshi et al. [58] observed that a saccular formation of the $\mathrm{FL}$, which is defined as partial thrombosis in the distal portion of the FL with proximal filling of the $\mathrm{FL}$, forming a blind sac, was a significant predictor of aortic growth compared with nonsaccular partial FL thrombosis [58]. These findings were confirmed by another more recent study [46].

\section{Entry Tear}

A patent primary entry site in the thorax was predictive for aortic enlargement compared with an absent primary entry site [30]. Tolenaar et al. [63,64] demonstrated that a short distance of the primary entry tear to the subclavian artery and the number of entry tears at initial imaging detected between the true and false lumen may be important predictors of aneurysmal dilation. Patients with one entry tear at presentation show a higher growth rate than patients with more entry tears [64]. The highest growth rates were seen in patients with a single entry tear located within $5 \mathrm{~cm}$ of the left subclavian artery. Sueyoshi et al. [65] showed that the presence of multiple false lumens was an independent predictor of dissectionrelated death (HR 5.6) compared to patients with conventional dissection consisting of one true and one false lumen ( $18 \%$ versus $82 \%$ survival at 10 years, respectively). Additionally, Evangelista et al. [43] demonstrated that patients with an entry tear of $\geq 10 \mathrm{~mm}$ had a higher incidence of dissection-related complications (HR 5.8) and a higher median growth rate than those with an entry tear measuring $<10 \mathrm{~mm}$.

The position of the primary entry tear is also of importance. A FL located in the inner curvature of the aorta was associated with aortic enlargement in a study that was in concordance with another experience that showed that a primary entry tear at the concavity of the distal aortic arch is a predictor of complications in acute TBAD (HR 1.8) $[33,46]$. In addition, Tsai et al. [66] showed that a proximal location of the entry tear may cause aortic expansion. In the series by Kitamura et al. [67], the primary entry at the outer curvature of the distal aortic arch was associated with a lower chance of thrombosis of the descending false lumen, and a primary entry at the inner curvature of the distal aortic arch was associated with a higher risk of complication in acute TBAD $[33,68]$.

\section{Ulcer-like Projection (ULP)}

ULPs are described as projections of the site of the intimal tear, the site of the occlusion, or the detachment of origins of side branches and penetrating atherosclerotic ulcers. However, the definition of ULPs still remains fuzzy and needs further clarification in future studies $[69,70]$.

The study by Jang et al. [71] showed relatively high late aortic event rates in patients with completely thrombosed false lumens, which was explained by the high prevalence of an entry tear (ULP) in these patients. In this study, any blood-filled pouch projecting into the thrombosed false lumen was defined as a ULP, which was detected by CT in $62.3 \%$ of patients with a completely thrombosed false lumen.

A summary of the clinical and radiological predictive findings is given in Table 3.

\section{Predictors for Various Clinical Outcomes}

\section{Aortic Growth Rate}

Multivariate linear regression analysis by Tolenaar et al. [46] showed that male gender (repeatability coefficient $[R C], 2.32 ; 95 \%$ confidence interval [Cl], 0.60-4.04; $P=0.005$ ) and a saccular formation of the $\mathrm{FL}(\mathrm{RC}, 4.94 ; 95 \% \mathrm{Cl}, 2.07-7.81 ; P=0.001)$ were associated with a significantly increased aortic growth rate. Increasing age $(\mathrm{RC},-0.13 ; 95 \% \mathrm{Cl},-0.23$ to -0.04 ; $P=0.005)$, increased number of intimal tears $(95 \% \mathrm{Cl}$, -2.40 to $-0.43 ; P=0.005)$, FL located on the outer aortic curvature $(95 \% \mathrm{Cl},-4.30$ to $-0.38 ; P=0.019)$, and a circular configuration of the thrombosed lumen (RC, $-2.83 ; 95 \%, \mathrm{Cl}-5.35$ to $-0.32 ; P=0.027$ ) were correlated with decreased growth rate [46].

\section{Dissection-Related Death}

Supposedly, a large initial FL thickness and patency are independent prognostic factors for poor outcomes in TBAD [31,32,57,72,73]. Ueki et al. [73] demonstrated that, on multivariate analysis, false lumen thickness (HR, 1.14; 95\% Cl, 1.03-1.27; $P=0.013$ ) was a significant predictor of dissection-related death. Consistent with previous reports, patients with an initial FL of $>15 \mathrm{~mm}$ showed a higher rate of dissection-related death $(P<0.001)$.

\section{Aortic Events}

In previous studies prognostic factors for aortic events, such as increasing aortic diameter, FL patency, 
Table 3. Clinical and Radiological Predictive Findings

Influence Mortality

(Reference Source)
Influence Growth Rate or Rupture (Reference Source)

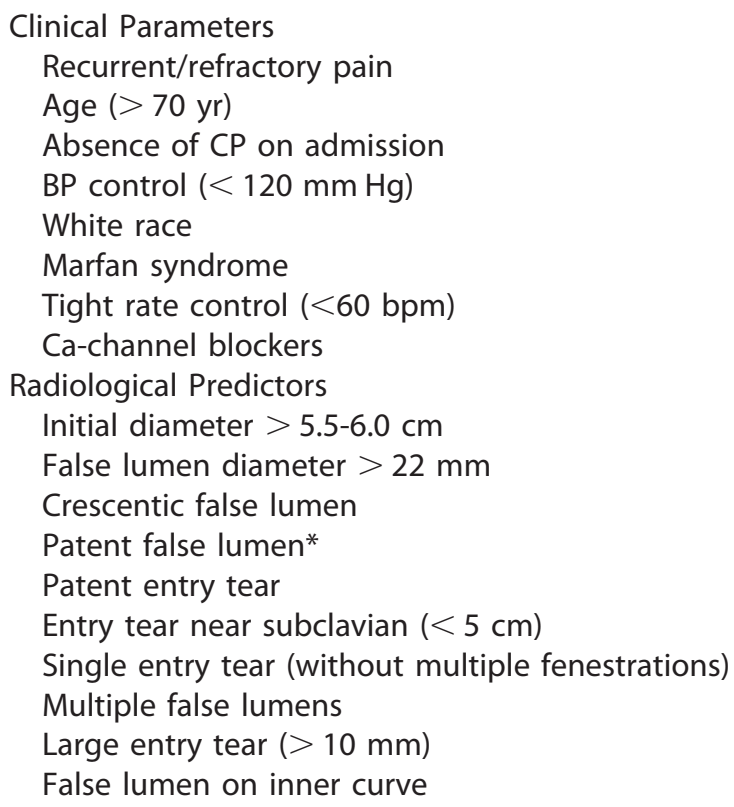

介 OR $3.3[25]$

介 OR $5.1[25]$

介 OR $3.5[25]$

$\begin{aligned} & \Downarrow[44,46-48] \\ & \Downarrow[32,43-46] \\ & \Downarrow[32,43-46] \\ & \Downarrow[32,43-46] \\ & \Downarrow[32,43-46] \\ & \\ \Uparrow 4 \times & \Uparrow[13,52,56] \\ & \Uparrow[32] \\ \Uparrow[31] & \Uparrow[46] \\ & \Uparrow[48-51,50,55,57,58] \\ & \Uparrow[30] \\ & \Uparrow[63,64,66] \\ & \Uparrow[63,64] \\ \text { OR 5.6 [65] } & \Uparrow[43] \\ & \Uparrow[33,46]\end{aligned}$

*Partial thrombosis controversial, in terms of negative impact on natural history $[15,31,46,58,59,60,61]$.

and location of the intimal tear, have been reported $[30,43,49-51,55,57,58,68,69,74,75]$. In the study by Ueki et al. [73], multivariate Cox regression analysis showed a descending aortic diameter (HR, 1.14; 95\% $\mathrm{Cl}, 1.09-1.19 ; P<0.001)$ and the presence of a proximal entry tear (HR, 2.90; 95\% Cl, 1.47-5.75; $P=0.002$ ) to be a significant predictor of aortic events. Previous reports and some recent studies provided an aortic diameter cut-off value of 40-45 $\mathrm{mm}$ [30,49$51,55,69,73,74]$ and reported the proximal location of the entry tear as a risk factor for late aortic events $[43,68,73,75]$.

\section{All-Cause Mortality}

In the study by Ueki et al. [73], Cox regression multivariate analysis after univariate analysis of allcause mortality showed age (HR, 1.08; $95 \% \mathrm{Cl}, 1.03-$ 1.14; $P<0.001)$ and $\mathrm{FL}$ thickness (HR, $1.10 ; 95 \% \mathrm{Cl}$, $1.02-1.19 ; P=0.01$ ) to be independent prognostic factors for mortality.

Combining these clinical and radiological predictors may be essential to implement a patient-specific approach designed to intervene only in those patients who are at high risk of developing complications to improve the long-term outcomes of patients with uncomplicated TBAD.

\section{Meta-analysis}

TEVAR for complicated TBAD has demonstrated improved survival compared to open surgery. It effectively reduces aneurysmal expansion, induces $\mathrm{FL}$ thrombosis, and decreases postdischarge mortality [31,76-79].

Given the limited number of patients in most of the studies, we conducted this meta-analysis on the current role of TEVAR in the treatment of predominantly uncomplicated TBAD compared to best medical treatment in comparative studies.

An extensive electronic health database search was performed on all articles published from January 2006 up to July 2014 describing the management of acute Type B aortic dissection. The search was performed using exploded medical subject heading (MeSH) terms: "acute type B aortic dissection," "chronic type B aortic dissection," "complicated," "uncomplicated," "medical treatment," "surgical treatment," "open re- 
Cumulative 30-day all-cause mortality, mixed acute TBAD

\begin{tabular}{lcr}
\hline \multicolumn{1}{c}{ Study name } & & \\
& $\begin{array}{c}\text { Odds } \\
\text { ratio }\end{array}$ & p-Value \\
Shah & 0,816 & 0,225 \\
Janczak & 0,542 & 0,634 \\
Trimarchi & 1,483 & 0,620 \\
ADSORB & 1,034 & 0,987 \\
Qin & 1,943 & 0,662 \\
Chemelli Steingruber & 2,374 & 0,258 \\
& 0,878 & 0,410
\end{tabular}

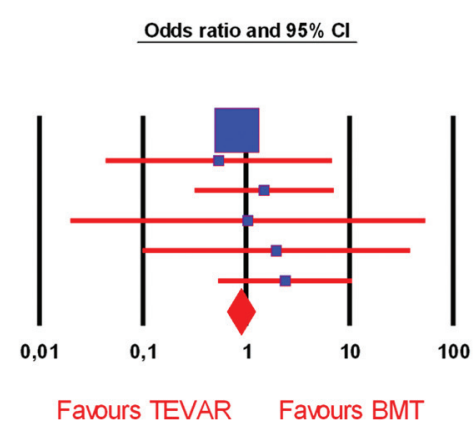

Figure 1. Cumulative 30-day all-cause mortality, mixed acute Type B aortic dissection (TBAD).

Cumulative 30-day all-cause mortality, predominantly chronic uncomplicated TBAD

Study name

$\begin{array}{lcc} & \begin{array}{c}\text { Odds } \\ \text { ratio }\end{array} & \text { p-Value } \\ \text { Jia (chronic uncomplicated) } & 0,455 & 0,695 \\ \text { Nienaber (chronic uncomplicated) } & 3,554 & 0,122 \\ \text { Nozdrzykowskj (chronic mixd) } & 2,133 & 0,545 \\ & 2,497 & 0,159\end{array}$

Odds ratio and $95 \%$

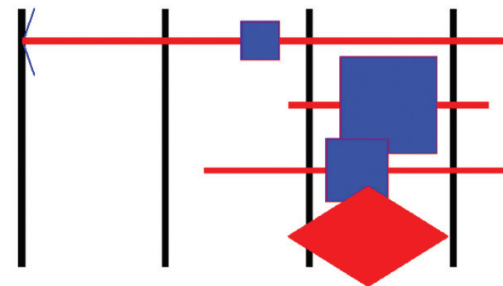

10

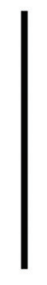

100

\section{Favours TEVAR Favours BMT}

Figure 2. Cumulative 30-day all-cause mortality, chronic Type B aortic dissection (TBAD), mostly uncomplicated.

pair," and "endovascular treatment." Publications were retrieved through electronic search engines (Medline, Embase, Scopus, Google Scholar, Ovid, and the Cochrane Library). All studies were independently assessed, and full texts of potentially eligible studies were retrieved. In addition, the reference lists of all retrieved articles were examined for further relevant series.

Studies were included in the present review if (1) the index aortic pathology was acute or chronic TBAD with focus on uncomplicated TBADs; (2) the applied treatment options were BMT or TEVAR; (3) they stated the incidence of at least one of the basic outcome criteria. Primary end points evaluated in the study included 30-day and 5-year mortality rates. Secondary end points were paraplegia or paraparesis rates as well as stroke and remodeling rate.
When multiple publications on the same patient population were identified or study populations overlapped, only the latest report was included, unless the reported outcomes were mutually exclusive. Furthermore, some studies included mixed pathologies with complicated and uncomplicated, acute and chronic TBAD as a subset of the entire study cohort. These were included in the present review if separate data for the patient subgroups were provided.

As a result, the present meta-analysis was not based entirely on comparative randomized studies, but included retrospective comparative studies on both treatment modalities (TEVAR + BMT versus BMT alone), as well.

In patients with mixed (complicated and uncomplicated) acute TBAD there was no significant difference between TEVAR and BMT groups regarding the cumu- 
Five-year all-cause mortality, chronic uncomplicated TBAD

Study name

$\begin{array}{lrr}\text { Nienaber (INSTEAD, ITT) } & \begin{array}{c}\text { Odds } \\ \text { ratio }\end{array} & \mathrm{p} \text {-Value } \\ \text { Jia } & 0,529 & 0,189 \\ & 0,325 & 0,000 \\ & 0,373 & 0,000\end{array}$

Odds ratio and $95 \% \mathrm{Cl}$

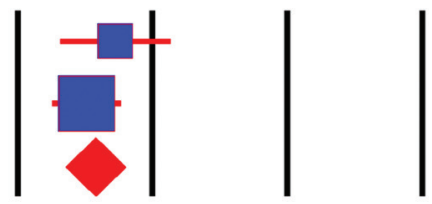

10

100

Favours TEVAR Favours BMT

Figure 3. Five-year all-cause mortality, chronic uncomplicated Type B aortic dissection (TBAD).

Five-year aorta related mortality, chronic uncomplicated TBAD

Study name

$\begin{array}{lrr}\text { Nieraber (INSTEAD, ITT) } & \begin{array}{r}\text { Odds } \\ \text { ratio }\end{array} & \text { p-Value } \\ \text { Jia } & 0,316 & 0,038 \\ & 0,172 & 0,000 \\ & 0,226 & 0,000\end{array}$

Odds ratio and $95 \% \mathrm{Cl}$
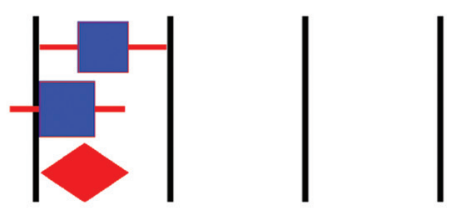

0,01

$0,1 \quad 1$

10

100

Favours TEVAR Favours BMT

Figure 4. Five year aorta-related mortality, chronic uncomplicated Type B aortic dissection (TBAD).

lative 30-day all-cause mortality (six studies [61,78,80,82-85]; TEVAR: $n=775$, BMT: $n=4616$, $\mathrm{OR}=0.878, P=0.410 ; \mathrm{I}^{2}=0.00, P=0.740$ ) (Fig. 1).

Cumulative 30-day all-cause mortality in patients with predominantly chronic uncomplicated TBAD was similar between TEVAR and BMT groups (three studies [27,80,81]; TEVAR: $n=312, \mathrm{BMT}: n=196, \mathrm{OR}=2.497$, $P=0.159 ; I^{2}=0.00, P=0.631$ ) (Fig. 2).

In contrast to the 30-day mortality, the five-year all-cause mortality in patients with chronic uncomplicated TBAD was significantly reduced in the TEVAR group compared to the BMT group (two studies [27,80]; TEVAR: $n=280$, BMT: $n=163, \mathrm{OR}=0.373$, $P=0.000 ; I^{2}=0.00, P=0.397$ ) (Fig. 3).

Additionally, in patients with chronic uncomplicated TBAD the 5-year aorta-related mortality was significantly lower in the TEVAR group compared to the BMT group (two studies [27,80]; TEVAR: $n=280$, BMT: $n=163$, OR $=0.226, P=0.000 ; I^{2}=0.00, P=$ 0.419) (Fig. 4).

Paraplegia or paraparesis (permanent or temporary) rates in patients with chronic uncomplicated TBAD were similar between TEVAR and BMT groups, though with a slight but not significant advantage for the BMT group (three studies [27,80,81]; TEVAR: $n=312$, BMT: $n=196$, $\mathrm{OR}=3.815, P=0.141 ;\left.\right|^{2}=0.00, P=0.834$ ) (Fig. 5).

The odds for stroke did not differ significantly between TEVAR versus BMT in patients with chronic uncomplicated TBAD, although a trend toward less stroke rates in the BMT group was indicated (two studies [27,81]; TEVAR: $n=104$, BMT: $n=101$, OR $=$ 3.027, $\left.P=0.341 ; I^{2}=0.00, P=0.964\right)$ (Fig. 6). 
Paraplegia or paraparesis, chronic uncomplicated TBAD

Study name

$\begin{array}{lrr}\text { Jia } & \begin{array}{c}\text { Odds } \\ \text { ratio }\end{array} & \mathrm{p} \text {-Value } \\ \text { Nienaber } & 2,312 & 0,590 \\ \text { Nozdrzy konski } & 2,874 & 0,520 \\ & 7,949 & 0,176 \\ & 3,815 & 0,141\end{array}$

Odds ratio and $95 \% \mathrm{Cl}$

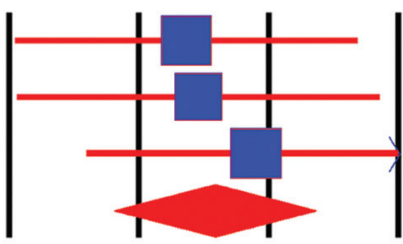

0,1
100

Favours TEVAR Favours BMT

Figure 5. Paraplegia or paraparesis, chronic uncomplicated Type B aortic dissection (TBAD).

Stroke, chronic uncomplicated TBAD

Study name

$\begin{array}{lrr} & \begin{array}{r}\text { Odds } \\ \text { ratio }\end{array} & \text { p-Value } \\ \text { Nieraber } & 2874 & 0,520 \\ \text { Nozdzylonsti } & 3,190 & 0,482 \\ & 3,027 & 0,341\end{array}$

Odds ratio and $95 \% \mathrm{Cl}$

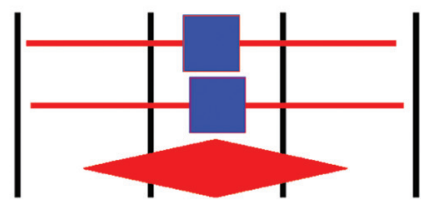

0,1 1

10

100

Favours TEVAR Favours BMT

Figure 6. Stroke, chronic uncomplicated Type B aortic dissection (TBAD).

In patients with chronic uncomplicated TBAD, the remodeling rate was significantly higher in the TEVAR group compared to the BMT group (two studies $[27,80]$; TEVAR: $n=212$, BMT: $n=118$, OR $=47.983$, $\left.P=0.00 ; 1^{2}=0.00, P=0.466\right)$ (Fig. 7).

\section{Study Limitations}

As always, a meta-analysis can only be as good as the underlying data and, therefore, the present metaanalysis should be interpreted with caution. The most important shortcoming is the low number of randomized trials comparing TEVAR versus optimal medical treatment in patients with TBAD. In addition to that, the randomized trials included in the present metaanalysis are characterized by relatively low patient numbers $[23,83]$. As a result, in all but one end point (30-day all-cause mortality in complicated and uncomplicated acute TBAD) the meta-analysis relies on only two or three studies and in all end points only one randomized controlled trial is included for metaanalysis. Generally, nonrandomized studies are much more prone to various types of bias. Furthermore, the meta-analysis of the end point 30-day all-cause mortality in complicated and uncomplicated acute TBAD is largely influenced by the administrative database analysis by Shah et al. [85] due to its huge number of patients.

\section{Summary}

This review of the comparative studies of patients treated either with TEVAR or BMT for uncomplicated 
Remodeling rate, chronic uncomplicated TBAD

Study name

$\begin{array}{lrr} & \begin{array}{r}\text { Odds } \\ \text { ratio }\end{array} & \text { p-Value } \\ \text { Jia } & 58,750 & 0,000 \\ \text { Nienaber } & 34,364 & 0,000 \\ & 47,983 & 0,000\end{array}$

Odds ratio and $95 \% \mathrm{Cl}$

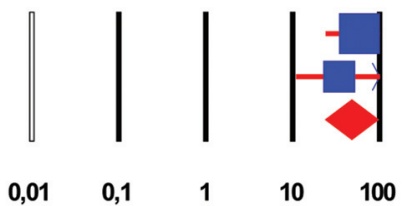

Favours BMT Favours TEVAR

Figure 7. Remodeling rate, chronic uncomplicated Type B aortic dissection (TBAD).

TBAD was an attempt to overcome the power limitation of smaller comparative studies.

Although the selected studies are not homogenous (with the risk of selection bias), the present review strongly suggests that TEVAR may be beneficial compared to BMT in the treatment of uncomplicated Stan-

ford Type B dissection, which is in agreement with the findings of the INSTEAD-XL trial. However, the early TEVAR-related deaths and complications, as well as trends toward higher paraplegia and stroke rates, raise concerns that moderate the better survival with TEVAR at five years.

Given the need for surgical intervention in upward of $20 \%$ of patients managed with BMT, it is imperative that future studies help identify characteristics of this cohort of patients that may be best treated with initial endograft repair.

\section{Conflict of Interest}

The authors have no conflict of interest relevant to this publication.

\section{Comment on this Article or Ask a Question}

\section{References}

1. Nienaber CA, Powell JT. Management of acute aortic syndromes. Eur Heart J. 2012;33: 26-35b. 10.1093/eurheartj/ehr186

2. Olsson C, Thelin S, Ståhle E, Ekbom A, Granath F. Thoracic aortic aneurysm and dissection: increasing prevalence and improved outcomes reported in a nationwide population-based study of more than 14,000 cases from 1987 to 2002. Circulation. 2006;114: 2611-2618. 10.1161/CIRCULATIONAHA.106. 630400

3. Winnerkvist A, Lockowandt U, Rasmussen $E_{,}$ Rådegran K. A prospective study of medically treated acute type $B$ aortic dissection. Eur J Vasc Endovasc Surg. 2006;32(4):349355. 10.1016/j.ejvs.2006.04.004

4. Parsa $C J$, Williams JB, Bhattacharya SD, Wolfe WG, Daneshmand MA, McCann RL, et al. Midterm results with thoracic endovascular aortic repair for chronic type $B$ aortic dissection with associated aneurysm. J Thorac Cardiovasc Surg. 2011;141:322-327. 10.1016/j. jtcvs.2010.10.043

5. Carpenter SW, Kodolitsch YV, Debus ES, Wipper S, Tsilimparis N, Larena-Avellaneda A, et al. Acute aortic syndromes: definition, prognosis and treatment options. J Cardiovasc Surg (Torino). 2014;55(2 Suppl 1):133-144.

6. Fattori R, Cao P, De Rango P, Czerny M, Evangelista $A$, Nienaber $C$, et al. Interdisciplinary expert consensus document on management of type B aortic dissection. J Am
Coll Cardiol. 2013;61:1661-1678. 10.1016/j. jacc.2012.11.072

7. Hagan PG, Nienaber CA, Isselbacher EM, Bruckman D, Karavite DJ, Russman PL, et al. The International Registry of Acute Aortic Dissection (IRAD): new insights into an old disease. JAMA. 2000;283:897-903. 10.1001/ jama.283.7.897

8. Nienaber CA, von Kodolitsch Y. [Metaanalysis of the prognosis of thoracic aortic dissection: changing mortality in the last four decades]. Herz. 1992;17:398-416.

9. Karthikesalingam A, Holt PJ, Hinchliffe RJ, Thompson MM, Loftus IM. The diagnosis and management of aortic dissection. Vasc Endovascular Surg. 2010;44:165-169. 10.1177/ 1538574410362118

10. Svensson L. Aortic dissection endovascular stenting: less pain, survival gain? Ann Thorac Surg. 2009;87:1332-1333. 10.1016/j.athoracsur. 2009.03.053

11. Estrera AL, Miller CC, Goodrick J, Porat EE, Achouh PE, Dhareshwar J, et al. Update on outcomes of acute type B aortic dissection. Ann Thorac Surg. 2007;83:S842-S845; discussion S846-S850. 10.1016/j.athoracsur.2006.10.081

12. Golledge J, Eagle KA. Acute aortic dissection. Lancet. 2008;372:55-66. 10.1016/S01406736(08)60994-0

13. Davies RR, Goldstein LJ, Coady MA, Tittle SL, Rizzo JA, Kopf GS, et al. Yearly rupture or dissection rates for thoracic aortic aneurysms: simple prediction based on size. Ann
Thorac Surg. 2002;73:17-27; discussion 2728. 10.1016/S0003-4975(01)03236-2

14. Yu HY, Chen YS, Huang SC, Wang SS, Lin FY. Late outcome of patients with aortic dissection: study of a national database. Eur J CardiothoracSurg.2004;25:683-690.10.1016/ j.ejcts.2003.12.041

15. Bernard Y, Zimmermann H, Chocron S, Litzler JF, Kastler B, Etievent JP, et al. False lumen patency as a predictor of late outcome in aortic dissection. Am J Cardiol. 2001;87:1378-1382. 10.1016/ S0002-9149(01)01556-9

16. Suzuki T, Isselbacher EM, Nienaber CA, Pyeritz RE, Eagle KA, Tsai TT, et al. Typeselective benefits of medications in treatment of acute aortic dissection (from the International Registry of Acute Aortic Dissection [IRAD]). Am J Cardiol. 2012;109:122127. 10.1016/j.amjcard.2011.08.012

17. Erbel R, Alfonso F, Boileau C, Dirsch O, Eber B, Haverich A, et al. Diagnosis and management of aortic dissection. Eur Heart J. 2001; 22:1642-1681. 10.1053/euhj.2001.2782

18. Tolenaar JL, van Bogerijen GH, Eagle KA, Trimarchi S. Update in the management of aortic dissection. Curr Treat Options Cardiovasc Med. 2013;15:200-213. 10.1007/s11936012-0226-1

19. Tsai $\Pi$, Evangelista A, Nienaber CA, Trimarchi $S$, Sechtem U, Fattori R, et al. Long-term survival in patients presenting with type $A$ acute aortic dissection: insights from the International Registry of Acute Aortic Dissec- 
tion (IRAD). Circulation. 2006;114(1 Suppl): 1350-1356.

20. Jonker FH, Trimarchi S, Muhs BE, Rampoldi V, Montgomery DG, Froehlich JB, et al. The role of age in complicated acute type B aortic dissection. Ann Thorac Surg. 2013;96:21292134. 10.1016/j.athoracsur.2013.06.056

21. Umaña JP, Lai DT, Mitchell RS, Moore KA, Rodriguez $\mathrm{F}$, Robbins RC, et al. Is medical therapy still the optimal treatment strategy for patients with acute type B aortic dissections? J Thorac Cardiovasc Surg. 2002;124: 896-910. 10.1067/mtc.2002.123131

22. Trimarchi $S$, Eagle KA, Nienaber CA, Pyeritz $\mathrm{RE}$, Jonker FH, Suzuki T, et al. Importance of refractory pain and hypertension in acute type $B$ aortic dissection: insights from the International Registry of Acute Aortic Dissection (IRAD). Circulation. 2010;122:12831289. 10.1161/CIRCULATIONAHA.109. 929422

23. Nienaber CA, Rousseau H, Eggebrecht $\mathrm{H}$, Kische S, Fattori R, Rehders TC, et al. Randomized comparison of strategies for type B aortic dissection: the INvestigation of STEnt Grafts in Aortic Dissection (INSTEAD) trial. Circulation. 2009;120:2519-2528. 10.1161/ CIRCULATIONAHA.109.886408

24. Clough RE, Mani K, Lyons OT, Bell RE, Zayed $H A$, Waltham M, et al. Endovascular treatment of acute aortic syndrome. J Vasc Surg. 2011;54:1580-1587. 10.1016/j.jvs.2011.07. 034

25. Clough RE, Albayati MA, Donati T, Taylor PR. Uncomplicated type B dissections: which patients should be treated? Lessons learned from the recent literature. J Cardiovasc Surg (Torino). 2014;55(2 Suppl 1):145-150.

26. Bossone E, Pyeritz RE, O'Gara P, Harris KM, Braverman AC, Pape $L$, et al. Acute aortic dissection in blacks: insights from the International Registry of Acute Aortic Dissection. Am J Med. 2013;126:909-915. 10.1016/j. amjmed.2013.04.020

27. Nienaber $C A$, Kische $S$, Rousseau $H$, Eggebrecht H, Rehders TC, Kundt G, et al. Endovascular repair of type $B$ aortic dissection: long-term results of the randomized investigation of stent grafts in aortic dissection trial. Circ Cardiovasc Interv. 2013;6:407-416. 10.1161/CIRCINTERVENTIONS.113.000463

28. Brunkwall J, Lübke T. Part one: for the motion. Level 1 evidence is necessary comparing TEVAR and medical management of uncomplicated type B aortic dissection. Eur J Vasc Endovasc Surg. 2013;46:274-277. 10. 1016/j.ejvs.2013.06.014

29. Elefteriades JA, Lovoulos CJ, Coady MA, Tellides G, Kopf GS, Rizzo JA. Management of descending aortic dissection. Ann Thorac Surg. 1999;67:2002-2005; discussion 20142019. 10.1016/S0003-4975(99)00428-2
30. Kato M, Bai H, Sato K, Kawamoto S, Kaneko $M$, Ueda $T$, et al. Determining surgical indications for acute type B dissection based on enlargement of aortic diameter during the chronic phase. Circulation. 1995;92(9 Suppl): II107-II112.

31. Tsai $\Pi$, Evangelista A, Nienaber CA, Myrmel $T$, Meinhardt G, Cooper JV, et al. Partial thrombosis of the false lumen in patients with acute type $B$ aortic dissection. N Engl J Med. 2007:357:349359. 10.1056/NEJMoa063232

32. Song JM, Kim SD, Kim JH, Kim MJ, Kang DH, Seo $\mathrm{JB}$, et al. Long-term predictors of descending aorta aneurysmal change in patients with aortic dissection. J Am Coll Cardiol. 2007;50:799-804. 10.1016/j.jacc.2007.03.064

33. Loewe C, Czerny M, Sodeck GH, Ta J, Schoder $M$, Funovics $M$, et al. A new mechanism by which an acute type $B$ aortic dissection is primarily complicated, becomes complicated, or remains uncomplicated. Ann Thorac Surg. 2012;93:1215-1222. 10. 1016/j.athoracsur.2011.12.020

34. Eggebrecht $H$, Herold $U$, Kuhnt $O$, Schmermund A, Bartel T, Martini $S$, et al. Endovascular stent-graft treatment of aortic dissection: determinants of post-interventional outcome. Eur Heart J. 2005;26:489-497. 10. 1093/eurheartj/ehi099

35. Fattori R, Lovato L, Buttazzi K, Russo V. Evolving experience of percutaneous management of type B aortic dissection. Eur J Vasc Endovasc Surg. 2006;31:115-122. 10.1016/j. ejvs.2005.10.016

36. Parker JD, Golledge J. Outcome of endovascular treatment of acute type B aortic dissection. Ann Thorac Surg. 2008;86:17071712. 10.1016/j.athoracsur.2008.06.074

37. Fattori R, Montgomery D, Lovato L, Kische S, Di Eusanio $M$, Ince $H$, et al. Survival after endovascular therapy in patients with type $B$ aortic dissection: a report from the International Registry of Acute Aortic Dissection (IRAD). J Am Coll Cardiol Cardiovasc Interv. 2013;6:876-882. 10.1016/j.jcin.2013.05.003

38. Fattori R, Tsai $\Pi$, Myrmel T, Evangelista A, Cooper JV, Trimarchi S, et al. Complicated acute type $B$ dissection: is surgery still the best option?: a report from the International Registry of Acute Aortic Dissection. J Am Coll Cardiol Cardiovasc Interv. 2008;1:395-402. 10. 1016/j.jcin.2008.04.009

39. Schoder M, Czerny M, Cejna M, Rand T, Stadler A, Sodeck GH, et al. Endovascular repair of acute type $B$ aortic dissection: longterm follow-up of true and false lumen diameter changes. Ann Thorac Surg. 2007;83: 1059-1066. 10.1016/j.athoracsur.2006.10. 064

40. Sachs T, Pomposelli F, Hagberg R, Hamdan A, Wyers M, Giles K, et al. Open and endovascular repair of type $B$ aortic dissection in the Nationwide Inpatient Sample. J Vasc
Surg. 2010;52:860-866; discussion 866. 10. 1016/j.jvs.2010.05.008

41. Suzuki T, Trimarchi S, Sawaki D, Grassi V, Costa E, Rampoldi V, et al. Circulating transforming growth factor-beta levels in acute aortic dissection. J Am Coll Cardiol. 2011;58: 775. 10.1016/j.jacc.2010.01.079

42. Trimarchi S, Sangiorgi G, Sang X, Rampoldi V, Suzuki T, Eagle KA, et al. In search of blood tests for thoracic aortic diseases. Ann Thorac Surg. 2010;90:1735-1742. 10.1016/j.athoracsur.2010.04. 111

43. Evangelista A, Salas A, Ribera A, FerreiraGonzález I, Cuellar H, Pineda V, et al. Longterm outcome of aortic dissection with patent false lumen: predictive role of entry tear size and location. Circulation. 2012;125: 3133-3141. 10.1161/CIRCULATIONAHA.111. 090266

44. Jonker FH, Trimarchi S, Rampoldi V, Patel HJ, O'Gara P, Peterson MD, et al. Aortic expansion after acute type $B$ aortic dissection. Ann Thorac Surg. 2012;94:1223-1229. 10.1016/j. athoracsur.2012.05.040

45. Kitada S, Akutsu K, Tamori Y, Yoshimuta T, Hashimoto H, Takeshita S. Usefulness of fibrinogen/fibrin degradation product to predict poor one-year outcome of medically treated patients with acute type B aortic dissection. Am J Cardiol. 2008;101:13411344. 10.1016/j.amjcard.2007.12.036

46. Tolenaar JL, van Keulen JW, Jonker FH, van Herwaarden JA, Verhagen HJ, Moll FL, et al. Morphologic predictors of aortic dilatation in type B aortic dissection. J Vasc Surg. 2013; 58:1220-1225. 10.1016/j.jvs.2013.05.031

47. Kodama K, Nishigami K, Sakamoto T, Sawamura $T$, Hirayama $T$, Misumi $H$, et al. Tight heart rate control reduces secondary adverse events in patients with type $B$ acute aortic dissection. Circulation. 2008;118(14 Suppl):S167S170. 10.1161/CIRCULATIONAHA.107.755801

48. Sueyoshi E, Sakamoto I, Hayashi K, Yamaguchi T, Imada T. Growth rate of aortic diameter in patients with type B aortic dissection during the chronic phase. Circulation. 2004; 110(11 Suppl 1):II256-II261.

49. Kunishige $H$, Myojin $K$, Ishibashi $Y$, Ishii $K$, Kawasaki M, Oka J. Predictors of surgical indications for acute type $B$ aortic dissection based on enlargement of aortic diameter during the chronic phase. Jpn J Thorac Cardiovasc Surg. 2006;54:477-482. 10.1055/s2006-923978, 10.1007/s11748-006-0039-9

50. Marui A, Mochizuki T, Mitsui N, Koyama T, Kimura F, Horibe M. Toward the best treatment for uncomplicated patients with type $B$ acute aortic dissection: A consideration for sound surgical indication. Circulation. 1999; 100(19 Suppl):II275-II280.

51. Marui A, Mochizuki T, Koyama T, Mitsui N. Degree of fusiform dilatation of the proximal descending aorta in type B acute aortic dis- 
section can predict late aortic events. J Thorac Cardiovasc Surg. 2007;134:1163-1170. 10. 1016/j.jtcvs.2007.07.037

52. Trimarchi S, Jonker FH, Hutchison S, Isselbacher EM, Pape LA, Patel HJ, et al. Descending aortic diameter of $5.5 \mathrm{~cm}$ or greater is not an accurate predictor of acute type B aortic dissection. J Thorac Cardiovasc Surg. 2011;142(3):e101-e107. 10.1016/j.jtcvs. 2010.12.032

53. Thrumurthy SG, Karthikesalingam A, Patterson BO, Holt PJ, Hinchliffe RJ, Loftus IM, et al. A systematic review of mid-term outcomes of thoracic endovascular repair (TEVAR) of chronic type B aortic dissection. Eur J Vasc Endovasc Surg. 2011;42:632-647. 10.1016/j. ejvs.2011.08.009

54. Grommes J, Greiner A, Bendermacher B, ErImeier $\mathrm{M}$, Frech $\mathrm{A}$, Belau $\mathrm{P}$, et al. Risk factors for mortality and failure of conservative treatment after aortic type B dissection. J Thorac Cardiovasc Surg. 2014;148:21552160.e1. 10.1016/j.jtcvs.2014.03.053

55. Onitsuka S, Akashi H, Tayama K, Okazaki T, Ishihara K, Hiromatsu S, et al. Long-term outcome and prognostic predictors of medically treated acute type B aortic dissections. Ann Thorac Surg. 2004;78:1268-1273. 10. 1016/j.athoracsur.2004.02.031

56. Nordon IM, Hinchliffe RJ, Holt PJ, Morgan R, Jahangiri M, Loftus IM, et al. Endovascular management of chronic aortic dissection in patients with Marfan syndrome. J Vasc Surg. 2009;50:987-991. 10.1016/j.jvs.2009.05.056

57. Akutsu K, Nejima J, Kiuchi K, Sasaki K, Ochi $M$, Tanaka $K$, et al. Effects of the patent false lumen on the long-term outcome of type B acute aortic dissection. Eur J Cardiothorac Surg. 2004;26:359-366. 10.1016/j.ejcts.2004. 03.026

58. Sueyoshi E, Sakamoto I, Uetani M. Growth rate of affected aorta in patients with type B partially closed aortic dissection. Ann Thorac Surg. 2009; 88:1251-1257. 10.1016/j.athoracsur.2009.06.023

59. Trimarchi S, Tolenaar JL, Tsai $\Pi$, Froehlich J, Pegorer M, Upchurch GR, et al. Influence of clinical presentation on the outcome of acute $B$ aortic dissection: evidences from IRAD. J Cardiovasc Surg (Torino). 2012;53: 161-168.

60. Erbel R, Oelert H, Meyer J, Puth M, MohrKatoly $S$, Hausmann D, et al. Effect of medical and surgical therapy on aortic dissection evaluated by transesophageal echocardiography. Implications for prognosis and therapy. The European Cooperative Study Group on Echocardiography. Circulation. 1993;87: 1604-1615. 10.1161/01.CIR.87.5.1604

61. Trimarchi $\mathrm{S}$, Tolenaar JL, Jonker FH, Murray B, Tsai TT, Eagle KA, et al. Importance of false lumen thrombosis in type B aortic dissection prognosis. J Thorac Cardiovasc Surg. 2013;
145(3Suppl):S208-S212.10.1016/j.jtcvs.2012. 11.048

62. Qin YL, Deng G, Li TX, Jing RW, Teng GJ. Risk factors of incomplete thrombosis in the false lumen after endovascular treatment of extensive acute type B aortic dissection. J Vasc Surg. 2012;56:1232-1238. 10.1016/j.jvs.2012. 04.019

63. Tolenaar JL, van Herwaarden JA, Verhagen $\mathrm{H}$, Moll FL, Muhs BE, Trimarchi S. Importance of entry tears in Type B aortic dissection prognosis. Ann Cardiothorac Surg. 2013;2: 631-632. 10.3978/j.issn.2225-319X.2013.09. 05

64. Tolenaar JL, van Keulen JW, Trimarchi S, Jonker $\mathrm{FH}$, van Herwaarden JA, Verhagen $\mathrm{HJ}$, et al. Number of entry tears is associated with aortic growth in type B dissections. Ann Thorac Surg. 2013;96:39-42. 10.1016/j. athoracsur.2013.03.087

65. Sueyoshi E, Nagayama H, Hayashida T, Sakamoto I, Uetani M. Comparison of outcome in aortic dissection with single false lumen versus multiple false lumens: CT assessment. Radiology.2013;267:368-375.10.1148/radiol. 12121274

66. Tsai $\Pi$, Schlicht MS, Khanafer K, Bull JL, Valassis DT, Williams DM, et al. Tear size and location impacts false lumen pressure in an ex vivo model of chronic type $B$ aortic dissection. J Vasc Surg. 2008;47:844-851. 10. 1016/j.jvs.2007.11.059

67. Kitamura T, Torii S, Oka N, Horai T, Nakashima K, Itatani K, et al. Key success factors for thoracic endovascular aortic repair for non-acute Stanford type B aortic dissection. Eur J Cardiothorac Surg. 2014;46:432-437; discussion 437. 10.1093/ejcts/ezu012

68. Weiss G, Wolner I, Folkmann S, Sodeck G, Schmidli J, Grabenwöger M, et al. The location of the primary entry tear in acute type $B$ aortic dissection affects early outcome. Eur J CardiothoracSurg.2012;42:571-576.10.1093/ ejcts/ezs056

69. Miyahara S, Mukohara N, Fukuzumi M, Morimoto $\mathrm{N}$, Murakami $\mathrm{H}$, Nakagiri $\mathrm{K}$, et al. Long-term follow-up of acute type $B$ aortic dissection: ulcer-like projections in thrombosed false lumen play a role in late aortic events. J Thorac Cardiovasc Surg. 2011;142: e25-e31. 10.1016/j.jtcvs.2011.02.015

70. Nienaber CA, Sievers HH. Intramural hematoma in acute aortic syndrome: more than one variant of dissection? Circulation. 2002; 106:284-285. 10.1161/01.CIR.0000023453. 90533.82

71. Jang YM, Seo JB, Lee YK, Chae EJ, Park SH, Kang JW, et al. Newly developed ulcer-like projection (ULP) in aortic intramural haematoma on follow-up CT: is it different from the ULP seen on the initial CT? Clin Radiol. 2008; 63:201-206. 10.1016/j.crad.2007.07.020
72. Chang CP, Liu JC, Liou YM, Chang SS, Chen JY. The role of false lumen size in prediction of in-hospital complications after acute type B aortic dissection. J Am Coll Cardiol. 2008; 52:1170-1176. 10.1016/j.jacc.2008.06.034

73. Ueki C, Sakaguchi G, Shimamoto T, Komiya T. Prognostic factors in patients with uncomplicated acute type B aortic dissection. Ann Thorac Surg. 2014;97:767-773; discussion 773. 10.1016/j.athoracsur.2013.10.038

74. Takahashi J, Wakamatsu Y, Okude J, Kanaoka T, Sanefuji Y, Gohda T, et al. Maximum aortic diameter as a simple predictor of acute type B aortic dissection. Ann Thorac Cardiovasc Surg. 2008;14:303-310.

75. Kitai T, Kaji S, Yamamuro A, Tani T, Kinoshita $M$, Ehara $N$, et al. Impact of new development of ulcer-like projection on clinical outcomes in patients with type B aortic dissection with closed and thrombosed false lumen. Circulation. 2010;122(11 Suppl):S74S80. 10.1136/heartjnl-2012-302089

76. Dake MD, Kato N, Mitchell RS, Semba CP, Razavi MK, Shimono T, et al. Endovascular stent-graft placement for the treatment of acute aortic dissection. N Engl J Med. 1999;340:1546-1552. 10. 1056/NEMM199905203402004

77. Dialetto G, Covino FE, Scognamiglio G, Manduca S, Della Corte A, Giannolo B, et al. Treatment of type $B$ aortic dissection: endoluminal repair or conventional medical therapy? Eur J Cardiothorac Surg. 2005;27:826830. 10.1016/j.ejcts.2005.02.002

78. Chemelli-Steingruber I, Chemelli A, Strasak A, Hugl B, Hiemetzberger R, Jaschke W, et al. Endovascular repair or medical treatment of acute type B aortic dissection? A comparison. Eur J Radiol. 2010;73:175-180. 10.1016/ j.ejrad.2008.09.031

79. Qing KX, Yiu WK, Cheng SW. A morphologic study of chronic type B aortic dissections and aneurysms after thoracic endovascular stent grafting. J Vasc Surg. 2012;55:12681275; discussion 1275-1276. 10.1016/j.jvs. 2011.11.099

80. Jia X, Guo W, Li TX, Guan S, Yang RM, Liu XP, Zhang $\mathrm{MH}$, Xiong J. The results of stent graft versus medication therapy for chronic type $B$ dissection. J Vasc Surg. 2013;57:406-414. 10. 1016/j.jvs.2012.08.064

81. Nozdrzykowski M, Etz CD, Luehr M, Garbade J, Misfeld M, Borger MA, et al. Optimal treatment for patients with chronic Stanford type B aortic dissection: endovascularly, surgically or both? Eur J Cardiothorac Surg. 2013;44: e165-e174; discussion e174. 10.1093/ejcts/ ezt291

82. Janczak D, Skóra J, Garcarek J, Litarski A, Merenda M, Wieraszko A. Own clinical observations of treatment outcome in acute type B aortic dissection. Pol Przegl Chir. 2012;84:23-30. 10.2478/v10035-012-0004-5 
83. Brunkwall J, Kasprzak P, Verhoeven E, Heijmen R, Taylor P. Endovascular repair of acute uncomplicated aortic type B dissection promotes aortic remodelling: 1 year results of the ADSORB trial. Eur J Vasc Endovasc Surg. 2014;48:285-291. 10.1016/j.ejvs.2014.05.012

84. Qin YL, Deng G, Li TX, Wang W, Teng GJ. Treatment of acute type-B aortic dissection: thoracic endovascular aortic repair or medi- cal management alone? J Am Coll Cardiol Cardiovasc Interv. 2013;6:185-191. 10.1016/ j.jcin.2012.11.004

85. Shah TR, Rockman CB, Adelman MA, Maldonado TS, Veith FJ, Mussa FF. Nationwide comparative impact of thoracic endovascular aortic repair of acute uncomplicated type B aortic dissections. Vasc Endovascular Surg. 2014;48: 230-233. 10.1177/1538574413518122
Cite this article as: Luebke T, Brunkwall J. Type B Aortic Dissection: A Review of Prognostic Factors and Meta-analysis of Treatment Options. Aorta 2014;2(6): 265-278. DOl: http://dx.doi.org/10.12945/ j.aorta.2014.14-040 